\title{
Analisis Potensi Pasar dan Atribut Pelayanan Rumah Sakit Islam Depok
}

\author{
Dumilah Ayuningtyas* Hidayani Fazriah**
}

\begin{abstract}
Abstrak
Di Kota Depok masyarakat muslim yang menjadi komunitas terbesar ( $91,94 \%$ ) merupakan pasar potensial rumah sakit. Tujuan penelitian ini adalah mendapat gambaran potensi pasar dan atribut pelayanan rumah sakit yang diharapkan masyarakat muslim. Penelitian yang menggunakan model SERVQUAL ini dimodifikasi dengan 4 karakteristik syariah marketing dan dikelompokkan dalam people, place, symbols, equipment, dan price. Desain penelitian menggunakan metode survey self administered questionaire. Sampel berjumlah 120 diambil dari pasien yang berobat di rumah sakit di Kota Depok. Selain itu, dilakukan studi kualitatif dengan metode indepth interview kepada pakar terkait. Atribut pelayanan rumah sakit Islam pilihan responden yang bersifat universal berupa bentuk pelayanan yang diinginkan. Atribut spesifik tersebut meliputi cara berpakaian, tata ruang, petunjuk arah kiblat, petunjuk dan perlengkapan wudhu pasien, disain interior Islami, mushola di setiap lantai. Atribut fasilitas berupa bimbingan pasien kritis dan bimbingan ruhani. Atribut tarif meliputi komitmen melayani pasien tak mampu, pelayanan tidak terpengaruh tarif kelas dan tidak sepenuhnya profit oriented. Dari hasil indeph interview pakar diformulasikan atribut pelayanan rumah sakit Islam yang bersifat universal dan spesifik. Atribut pelayanan spesifik meliputi aspek fisik, aspek SDM, dan aspek fasilitas. Atribut pembiayaan yang tidak ada pembedaan tarif, tidak menerapkan uang muka. Atribut prosedur pelayanan medis berupa pelayanan bersalin dengan konsep pure gender dan adanya standar operasional prosedur yang memperhatikan aspek layanan gender. Manajemen rumah sakit Islam perlu mempertimbangkan potensi pasar dan merealisasikan atribut universal dan spesifik.
\end{abstract}

Kata kunci : Pasar potensial, atribut servis, rumah sakit islam

\begin{abstract}
Muslim community as the largest population in Indonesia as well as in the city of Depok with the percentage of $91.94 \%$, has been considered as prospective market for Islamic-based business including hospital business. The objective of this study is to investigate the market potential and the service attributes of the Islamic hospitals. The design of study is analytic descriptive with quantitative approach using survey method through self administered questionnaires. The number of samples was 120 taken from the patients nursed in the hospitals in Depok. Qualitative approach was conducted using in-depth interview of related experts. The attributes of service of Islamic hospitals selected by the respondents were universal and specific. The universal attributes were the service models. The specific attribute which indicated Islamic services physically comprised of : Muslim costumes, availability of sign of the direction of kiblah, Islamic interior design, and availability of prayer room. The attributes of facilities including guide for critical patients by particular staff, and costumes for prayer for serious patients, and religious guide for the patients and their family. The attributes of price were to serve poor patients, the services are not influenced by the class tariff and not fully profit-oriented. The specific attributes of service including physical aspects, facility aspects, and human resources aspect. The attributes of costing comprise of: the absence of tariff differences, there is no deposit. The attributes of medical services consist of purely gender-based maternity services, and the existence standard operation procedures which considers the aspects gender-based services. The management of Islamic hospitals should consider their market potencies and implement the universal and specific attributes to enable them to perform Islamic high-quality services.
\end{abstract}

Key words : Potential market, services attribute, islamic hospital 
Dunia pelayanan kesehatan milik pemerintah maupun non pemerintah suka atau tidak suka harus mengikuti arus perubahan agar dapat bertahan dan berkembang menghadapi lingkungan yang dinamis. Penerapan prinsip-prinsip pemasaran dalam penyelenggaraan pelayanan kesehatan menjadi dapat dimengerti. ${ }^{1,2}$ Menurut Kasali diperlukan formulasi strategi pemasaran yang jitu antara lain dengan melakukan analisis segmentasi pasar sehingga dapat diketahui bagian pasar potensial yang hendak dibidik berikut kebutuhannya. Berdasarkan segmentasi pasar dipilih bagian tertentu dari pasar yang sangat luas, sehingga rumah sakit dapat berkonsentrasi memberikan pelayanan yang sesuai dengan keinginan pasar. ${ }^{3}$ Peta pemasaran Indonesia tampaknya mulai bergeser dari pasar rasional ke pasar emosional bahkan ke pasar spiritual. Konsumen tidak hanya mempertimbangkan fungsi, harga, cita rasa, ataupun prestise, tetapi juga nilai baik buruk, halal haram yang berhubungan dengan keyakinann mereka. ${ }^{4}$

Rumah Sakit Islam merupakan salah satu bentuk bisnis islami yang dalam keseluruhan prosesnya sesuai dengan akad dan prinsip-prinsip mu'amalah (bisnis) dalam Islam. Meskipun Indonesia bukan negara yang berlandaskan hukum islam, tetapi komposisi penduduk muslim yang mencapai $91,94 \%$, dapat dijadikan rujukan yang kuat untuk menjadikan bisnis berbasis islam sebagai pasar potensial. Kota Depok termasuk satu dari sekian banyak kota di Indonesia yang mayoritas penduduknya beragama islam. Berdasarkan data kantor Dinas Agama Kota Depok tahun 2006, dari jumlah total penduduk kota Depok yang berjumlah 1.141.451 jiwa, penduduk yang beragama islam berjumlah 1.049.435 jiwa atau sekitar 91,38\%. Hal ini makin memperkuat asumsi potensi pasar untuk bisnis keislaman di kota Depok. Sayangnya, kebangkitan semangat religius masyarakat muslim Depok di bidang pelayanan kesehatan, khususnya pelayanan rumah sakit belum terakomodasi secara optimal. Hingga kini, dari 12 rumah sakit yang ada di kota Depok, belum ada yang menyatakan diri Rumah Sakit Islam atau Rumah Sakit bernuansa islam. Padahal dalam terminologi marketing, Kotler dan Clarke menjelaskan tentang perbedaan needs dan wants. ${ }^{2}$ Needs adalah kebutuhan yang harus terpenuhi sebagaimana toeri hirarki kebutuhan Maslow, oleh sebab itu seorang pemasar harus mempelajari sistem nilai yang ada di masyarakat sebagaimana sistem kebutuhan mereka agar dapat memahami perilaku konsumen. Sedangkan wants adalah ketertarikan terhadap produk spesifik yang terdapat atribut-atribut produk yang sesuai dengan keinginan konsumen.

Penelitian ini bertujuan untuk mendapatkan gambaran potensi pasar dan atribut pelayanan rumah sakit islam yang diharapkan masyarakat muslim Depok, dengan menggunakan model servqual yang dimodifikasi dengan 4 karakteristik syariah marketing dan dikelompokkan dalam people, place, symbols, equipment, dan price. 5,6 Penelitian ini menggunakan instrumen kuesioner modifikasi dari beberapa instrumen penelitian sebelumnya dengan memfokuskan pada aspek fisik, perilaku SDM, fasilitas, pembiayaan, suasana rumah sakit yang bernuansa islami dan lokasi. Kemudian dilanjutkan dengan indepth interview dengan beberapa tokoh pakar muslim meliputi ulama, dokter, konsultan, pengelola rumah sakit Islam dan ilmuwan untuk mendeskripsikan atribut pelayanan Rumah Sakit Islam yang diharapkan kelak dapat diwujudkan pada sebuah Rumah Sakit Islam di Kota Depok.

\section{Metode}

Penelitian ini merupakan penelitian yang bersifat analitik descriptive yaitu untuk mendapatkan gambaran tentang potensi pasar dan atribut pelayanan rumah sakit Islam Depok. Penelitian dilakukan di bulan April-Mei 2007 di beberapa rumah sakit di kota Depok dengan metode survey. Selain itu juga, dilakukan indepth interview pada expert judgment yang merupakan praktisi manajemen beberapa rumah sakit Islam yang sudah ada, pakar syariah, konsultan perumahsakitan dan praktisi medis muslim.

\section{Hasil \\ Karakteristik Responden}

Penelitian dilakukan terhadap 120 responden muslim dewasa muda dengan rentang usia 20-39 tahun, proporsi responden perempuan $(68,33 \%)$ lebih tinggi dari lakilaki $(31,67 \%)$. Mayoritas responden berdomisili di kecamatan Sukmajaya dan Cimanggis, dua kecamatan terpadat di kota Depok. Umumnya telah berkeluarga, berpendidikan sarjana, dengan kalangan profesi, karyawan swasta dan ibu rumah tangga. Pendapatan responden berkisar 1-5 juta per bulan, dengan alokasi dana untuk kesehatan kurang dari seratus ribu rupiah per bulan dimana kebanyakan berasal dari kantong sendiri. Responden umumnya bermatapencaharian sebagai karyawan swasta $(26,67 \%)$, profesi $(29,17 \%)$ dan ibu rumah tangga $(26,67 \%)$.

\section{Potensi Pasar}

Fakta bahwa potensi pasar adalah penduduk dewasa muda yang umumnya menjadi pembuat keputusan (decision maker) dalam keluarganya. Manajemen rumah sakit sebaiknya membuat program pemasaran yang sesuai untuk kelompok usia ini agar dapat meningkatkan pemanfaatan Rumah Sakit Islam kelak. Faktor umur juga sangat berhubungan dengan kepuasan dimana kelompok usia muda lebih kritis dan tidak mudah dipuaskan dibandingkan kelompok usia tua. Seperti yang dapat dilihat pada Gambar 1. 
Gambar 1. Karakteristik Umur Responden Potensi Pasar Rumah Sakit Islam Depok

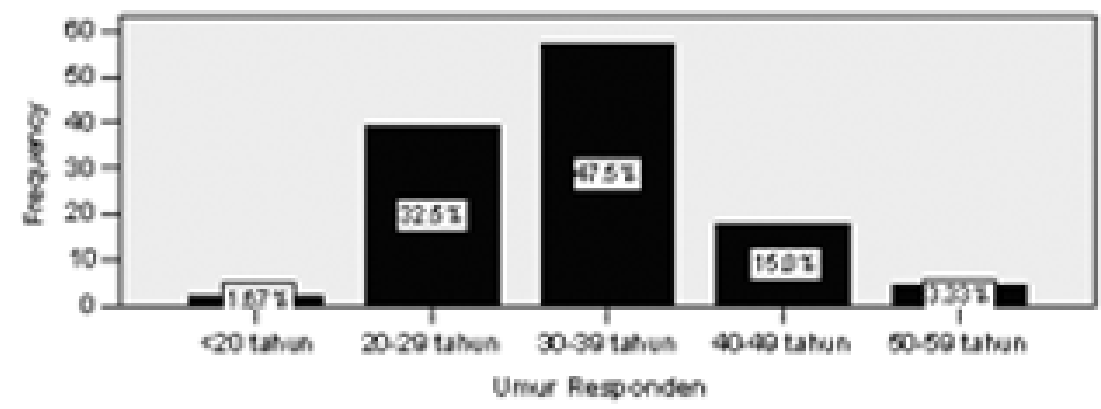

Gambar 2. Karakteristik Pendidikan Responden Potensi Pasar Rumah Sakit Islam Depok

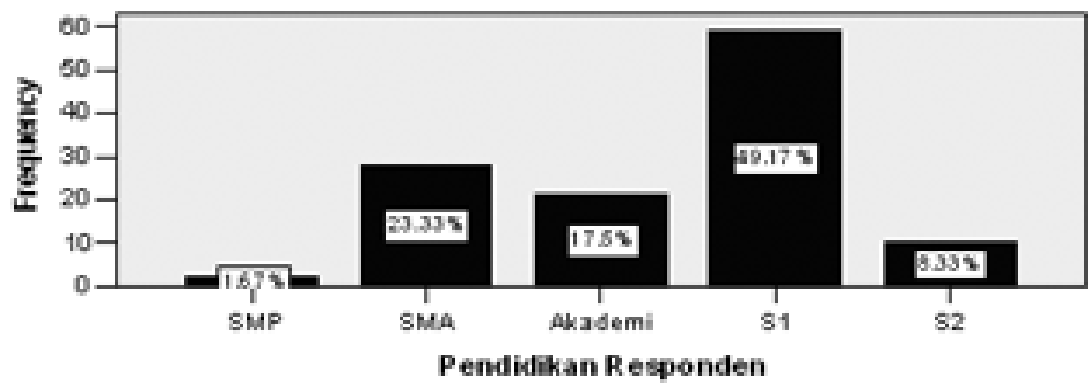

Gambar 3. Karakteristik Pekerjaan Responden Potensi Pasar Rumah Sakit Islam Depok

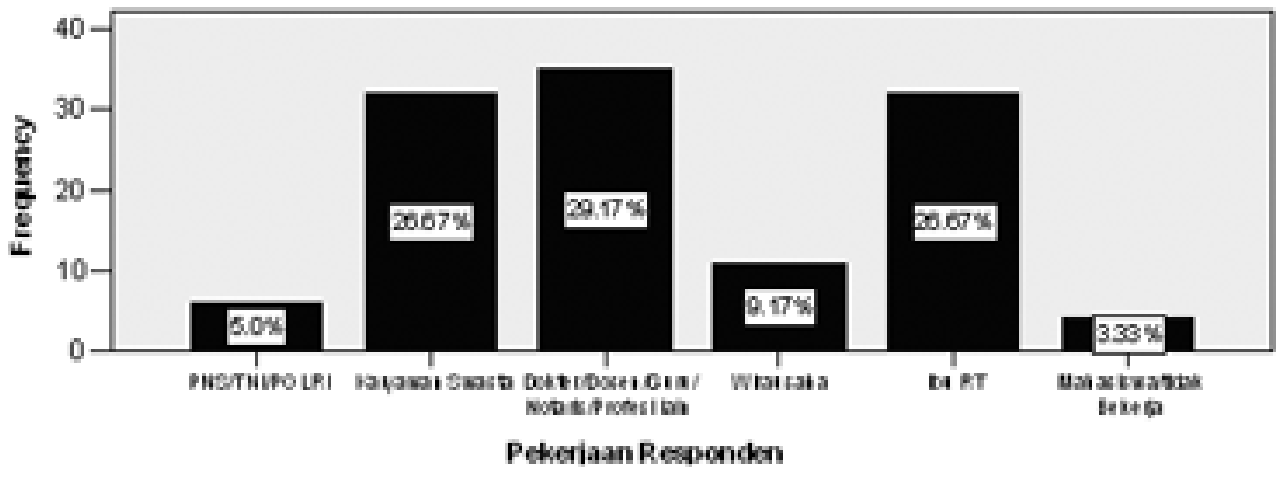

Potensi pasar dengan perbandingan perempuan dan laki-laki menjadi dasar kebijakan manajemen Rumah Sakit Islam untuk lebih mengantisipasi kendala dalam pelayanan berbasis gender yang menjadi atribut penting di Rumah Sakit Islam. Sebagai sebuah Rumah Sakit Islam maka harus tersedia petugas dan tempat untuk pasien perempuan dan laki-laki terutama untuk tindakan yang sangat erat hubungannya dengan aurat pasien. Mayoritas responden dan pasangannya berpendidikan sarjana $(49,17 \%)$ (Lihat Gambar 2). Pendidikan merupakan salah satu variabel yang menunjukkan kelas sosial (social classes) yang akan mempengaruhi perilaku sehat dan pola pemanfaatan pelayanan kesehatan di masyarakat. Berdasarkan pendapat tersebut dapat dimengerti bahwa semakin tinggi tingkat pendidikannya maka dalam pemanfaatan sarana kesehatannya akan memilih yang lebih berkualitas. Maka manajemen Rumah Sakit Islam perlu menyiapkan fasilitas dan petugas yang berkualitas tinggi sehingga dapat memenuhi tuntutan pasiennya dengan baik.

Pasar potensi merupakan pasangan suami-istri yang bekerja. Namun, yang juga menarik adalah jumlah ibu rumah tangga yang cukup besar $(26,67 \%)$ sehingga dapat menjadi input bagi manajemen untuk membuat prog- 
Gambar 4. Distribusi Pendapatan Responden Potensi Pasar Rumah Sakit Islam Depok

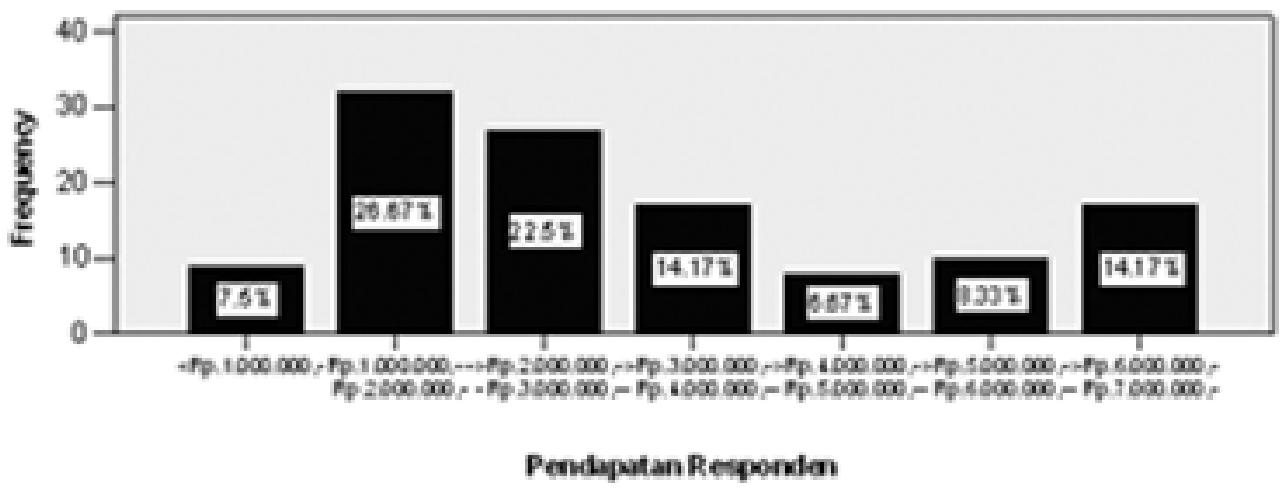

Gambar 5. Alokasi Biaya Kesehatan Responden Potensi Pasar Rumah Sakit Islam Depok

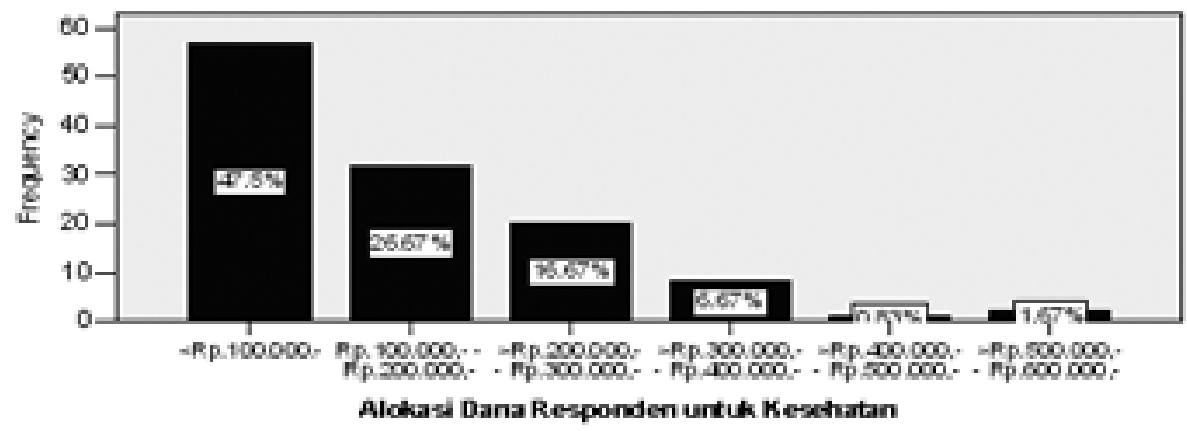

ram kesehatan bagi kaum ibu rumah tangga. Untuk potensi pasar yang bekerja di sektor swasta dan industri dapat dikembangkan kerja sama dengan pihak ketiga dalam hal ini perusahaan atau asuransi kesehatan. Karyawan swasta dan kalangan profesi merupakan potensi pasar Rumah Sakit Islam maka manajemen harus mempertimbangkan tersedianya fasilitas yang lengkap, nyaman dan berkualitas serta pelayanan yang cepat tanggap (responsivness), seperti terlihat pada gambar 3 . Sebagian responden sudah menikah (85\%) mengisyaratkan besarnya pasar potensial yang sudah berkeluarga, hal ini dikuatkan dengan komposisi usia penduduk dominan pada kelompok usia layak sudah berumah tangga. Potensi pasar Rumah Sakit Islam Depok dominan berasal dari kedua kecamatan yaitu Cimanggis dan Sukmajaya. Adanya rencana pembangunan jalan tol di Kecamatan Sukmajaya akan memperluas akses pasien tidak hanya dari kota Depok tapi juga dapat berasal dari Kabupaten Bogor dan Jakarta. Manajemen perlu memperhitungkan efek dari pembangunan jalan tol menjadi pertimbangan lokasi rumah sakit.

Pendapatan potensi pasar berkisar > Rp.2.000.000,- Rp.3.000.000,-. maka manajer menyusun tarif yang sesuai berbasis unit cost, ability to pay dan willingness to pay agar tarif dapat terjangkau segmen terbanyak dan rumah sakit tetap dapat memperoleh profit untuk meningkatkan kualitas pelayanannya (Gambar 4). Alokasi biaya kesehatan kurang dari Rp100.000,- per bulannya, hal ini sesuai dengan jumlah pendapatan responden pada umumnya. Mayoritas responden membayar biaya kesehatan dari kantong sendiri (out of pocket), implikasinya sebagian besar responden harus membayar jumlah yang cukup besar bila ada anggota keluarganya yang harus rawat inap atau operasi. Oleh karena itu, manajemen Rumah Sakit Islam dianjurkan untuk mempertimbangkan aspek keterjangkauan tarif agar tidak memberatkan pasar potensialnya atau menjalin kerja sama dengan asuransi kesehatan yang bila memungkinkan juga berbasis syariah (Gambar 5).

\section{Pembahasan}

Pada umumnya responden memilih berdasarkan kualitas pelayanan dokter dan perawat, fasilitas lengkap dan suasana bersih dan nyaman. Rumah sakit yang terbanyak dimanfaatkan adalah RSU Tugu Ibu, RSIA Hermina dan RSIA Tumbuh Kembang. Manajemen Rumah Sakit Islam disarankan untuk melakukan studi banding (benchmarking) dengan rumah sakit lain yang 
Tabel 1. Distribusi Menurut Alasan Memilih Rumah Sakit Responden Potensi Pasar, Rumah Sakit Islam Depok 2007

\begin{tabular}{|c|c|c|c|c|}
\hline Alasan Memilih Rumah Sakit & Ya & $\%$ & Tidak & $\%$ \\
\hline Kerjasama perusahaan/ ASKES dengan RS & 31 & 25,8 & 89 & 74,2 \\
\hline Pelayanan dokter dan perawat memuaskan & 86 & 71,7 & 34 & 28,3 \\
\hline Suasana bersih dan nyaman & 51 & 42,5 & 69 & 57,5 \\
\hline Fasilitas pemeriksaan lengkap & 53 & 44,2 & 67 & 55,8 \\
\hline Bangunan rumah sakit tampak mewah & 4 & 3,3 & 116 & 96,7 \\
\hline Lokasi dekat rumah/kantor & 45 & 37,5 & 75 & 62,5 \\
\hline Lainnya biaya terjangkau & 11 & 9,2 & 109 & 90,8 \\
\hline
\end{tabular}

Sumber : Data Primer

Tabel 2. Distribusi Aspek Keinginan Responden Terhadap Rumah Sakit Islam di Depok Tahun 2007

\begin{tabular}{lll}
\hline Faktor Keinginan & Jumlah & Persen \\
\hline Kehadiran RSI di Kota Depok & & \\
$\quad$ Perlu & 50 & $42 \%$ \\
$\quad$ Sangat perlu & 70 & $58 \%$ \\
Kesan Terhadap RSI selama ini & 25 & $21 \%$ \\
$\quad$ Bangunan RS terkesan tidak menarik dan kotor & 24 & $20 \%$ \\
$\quad$ Belum memfasilitasi pasien untuk beribadah kala sakit & 41 & $34 \%$ \\
$\quad$ Suasana Islami belum tergambarkan & 39 & $33 \%$ \\
$\quad$ Biaya berobat mahal & 21 & $18 \%$ \\
$\quad$ Hanya namanya Rumah Sakit Islam & 9 & $8 \%$ \\
$\quad$ Pelayanan di Rumah Sakit Islam sudah cukup baik & & \\
Nama RSI & 11 & $9.2 \%$ \\
$\quad$ Nama Rumah Sakit Harus Islami & 38 & $31.7 \%$ \\
$\quad$ Pelayanan Harus Islami & 67 & $55.8 \%$ \\
$\quad$ Nama maupun Pelayanan harus Islami & & \\
\hline
\end{tabular}

mempunyai keunggulan dalam berbagai aspek manajemen dan pelayanan. Rumah Sakit Islam harus mempunyai pelayanan yang tidak kalah unggul dari rumah sakit biasa yang terfavorit, tetapi mempunyai atribut khusus dan unik yang mencerminkan nilai-nilai islam dalam pelayanannya yang dapat dilihat pada tabel 1 dan 2 di atas.

Disimpulkan bahwa masyarakat Depok sudah sangat menginginkan hadirnya pelayanan kesehatan rumah sakit dengan warna islam di seluruh aspek pelayanannya. Hanya saja keinginan itu belum terpenuhi, karena sampai saat ini belum ada rumah sakit yang mensosialisasikan kepada pasarnya bahwa pengelolaannya bercorak islam. Namun demikian, realita pelayanan rumah sakit islam yang pernah mereka gunakan atau kunjungi sebelumnya belum sesuai harapan. Mayoritas responden mengungkapkan kesan yang bersifat negatif terhadap rumah sakit islam yang sudah ada. Beberapa informan menyatakan bahwa kunci kesuksesan berada pada faktor manusia, sedangkan faktor money, material, method dan machine menjadi penyerta.

Atribut fisik terpilih meliputi penampilan fisik petugas, kamar mandi, ruang perawatan terpisah antara pria dan wanita dan bangunan berkualitas merupakan bentuk pelayanan yang diinginkan oleh konsumen di rumah sakit pada umumnya yang merupakan atribut universal. Sedangkan, atribut fisik terpilih yang lain merupakan atribut spesifik Rumah Sakit Islam. Menurut peneliti segala sesuatu yang harus ada di sebuah rumah sakit dengan pelayanan berkualitas tentu juga harus ada di Rumah Sakit Islam apalagi aspek tangible yang sering memberikan kesan pertama memukau atau mengecewakan. Pada dasarnya pelayanan kesehatan adalah pelayanan jasa dengan salah satu karakteristik intangibility sehingga penting untuk tangibilize the intangible salah satunya dengan menonjolkan tangible clues seperti disain tempat, sumber daya manusia yang rapi, ramah dan responsif, peralatan pelengkap, simbol, logo dan harga. Tampilan fisik tidak hanya terbatas pada bangunan juga meliputi segala sesuatu yang berdaya tarik visual dan dapat terlihat langsung oleh pasien atau pengunjung rumah sakit.

Ditinjau dari sudut pandang islam maka tampilan fisik tidak boleh berlebihan mencerminkan kesederhanaan, bersih, menutup aurat, untuk bangunan mengikuti kaidah rumah islam. Menurut pandangan 
pakar arsitektur islam bahwa yang dianggap islami dalam arsitektur dan lingkungan islami adalah suasana yang diciptakan untuk mendorong ingatan kepada Allah, prinsip inilah yang perlu ditonjolkan dalam disain fisik dan interior ruangan Rumah Sakit Islam. Beberapa atribut fasilitas yang bersifat universal dapat disisihkan dari pembahasan dengan asumsi tidak terlalu spesifik untuk Rumah Sakit Islam, tetapi tetap harus disediakan, seperti memiliki peralatan yang lengkap, papan informasi dan penggunaan alat kesehatan dan obat yang halal.

Bimbingan sakaratul maut dan bimbingan ruhani sudah banyak dilakukan oleh Rumah Sakit Islam dan beberapa rumah sakit pemerintah di ibukota, tetapi belum semuanya dikoordinir secara struktural. Keberadaan direktur bina rohani yang memberi perhatian khusus pada perilaku islami dapat mempercepat perubahan citra kurang ramah, tidak disiplin dan tidak Islami yang melekat melalui pembentukan SDM yang lebih terprogram dan terevaluasi. Selain itu, petugas bimbingan ruhani dapat memotivasi beribadah, mendoakan dan mengajarkan pasien dan keluarga untuk tetap sabar, berikhtiar dan berdoa dalam menghadapi cobaan sakit. Hal tersebut perlu menjadi perhatian manajemen karena indikator keberhasilan bukan hanya kesembuhan jasmani tapi juga kekuatan iman.

Untuk lokasi rumah sakit, tidak ada hal yang spesifik, karena pertimbangan lokasi sama seperti rumah sakit biasa yaitu mudah diakses dan strategis. Sentuhan islam yang dapat ditambahkan adalah keberadaan masjid di area rumah sakit, seperti terlihat di beberapa Rumah Sakit Islam di Bandung, Jakarta dan Surabaya. Atribut SDM perlu mendapatkan perhatian yang lebih besar. Hasil analisis kuantitatif menunjukkan banyaknya variabel atribut SDM yang mendapatkan nilai tinggi ( $>90)$. Pendekatan kualitatif semua informan menegaskan kualitas SDM sangat menentukan tingkat kepuasan pelanggan dan menentukan citra pelayanan Rumah Sakit Islam. Merupakan tantangan yang berat bagi manajemen Rumah Sakit Islam untuk dapat membentuk SDM yang memahami dan perilaku islami serta tetap konsisten memberikan pelayanan yang benar-benar dijiwai oleh ruh islam. Bila kondisi itu dapat tercapai maka citra Rumah Sakit Islam di mata masyarakat dapat diperbaiki dan ditingkatkan.

Pendekatan kuantitatif diperoleh variabel atribut tarif yang antara lain meliputi bukti transaksi yang rinci, tarif terjangkau, pasien tidak mampu tetap dilayani yang banyak dilakukan oleh rumah sakit lain. Hampir semua rumah sakit memberlakukan perbedaan tarif berdasarkan kelas perawatan yang dipilih pasien dengan dalih subsidi silang, hal yang menarik buat peneliti adalah adanya rumah sakit syariah berskala internasional yang tidak menggunakan prinsip ini, tetapi satu jenis tarif untuk semua kelas perawatan.
Bila tarif dokter, obat, tindakan, pemeriksaan laboratorium, dan pemeriksaan diagnostik lainnya dibuat berdasarkan acuan yang tepat dan mempertimbangkan ability to pay dan willingness to pay maka, akan dapat terjangkau terutama buat golongan menengah ke bawah yang merupakan karakteristik pasar potensial di Kota Depok. Bisnis islam (syariah) bukanlah badan sosial semata tapi tetap sebuah unit bisnis untuk mencari keuntungan. Namun demikian, tujuan utama bisnis tersebut bukan hanya profit oriented, yang jauh lebih penting adalah memberikan kebahagiaan kepada setiap orang yang terlibat. Oleh sebab itu, tarif yang ditentukan tidak memberatkan, tidak perlu uang muka dan keluwesan pelunasan.

Aspek prosedur pelayanan medis tidak berdiri sebagai atribut tersendiri dalam instrumen kuantitatif tetapi dimasukkan dalam fasilitas. Peneliti menggali lebih jauh pada wawancara mendalam karena pertimbangan para pakar dan praktisi dapat memberikan informasi yang lebih spesifik. Aspek ini merupakan atribut yang spesifik yang sangat sulit ditemukan di rumah sakit. Peneliti dapat merabarasakan bagaimana seorang yang akan melahirkan atau operasi malu karena auratnya tidak dijaga oleh petugas dan tidak jarang menjadi bahan guyonan oleh petugas medis berbeda gender yang tidak berakhlak. Sebagai seorang muslim, peneliti ingin mencari informasi sejauh mana aurat dapat dijaga tanpa mengganggu prosedur medis. Informan yang merupakan praktisi medis semuanya tidak menganggap usaha menjaga aurat sebagai penyulit dan penghambat prosedur medis sehingga hal tersebut mungkin diterapkan dengan terlebih dahulu membuat SOP.

\section{Kesimpulan}

Karakteristik potensi pasar Rumah Sakit Islam di kota Depok adalah muslim berusia dewasa muda, dengan jenis kelamin perempuan sedikit lebih banyak daripara laki-laki. Mereka berpendidikan sarjana, dengan pekerjaan kalangan profesi dan karyawan swasta, mayoritas sudah berkeluarga dan sebagian besar tinggal di 2 kecamatan terpadat yaitu Sukmajaya dan Cimanggis. Mereka berpendapatan > Rp.2.000.000,- hingga Rp.3.000.000,per bulan dan alokasi biaya kesehatan kurang dari Rp. 100.000,- per bulan, yang mayoritas berasal dari kantong sendiri. Pola pemanfaatan layanan rumah sakit potensi adalah pelayanan dokter dan perawat, fasilitas lengkap dan suasana bersih dan nyaman. Selama ini paling sering menggunakan layanan kesehatan di RSU Tugu Ibu, RSIA Hermina dan RSIA Tumbuh Kembang. Seluruh potensi pasar sangat menginginkan kehadiran Rumah Sakit Islam di kota Depok.

\section{Saran}

Atribut pelayanan rumah sakit islam pilihan respon- 
den dan atribut pelayanan rumah sakit islam rekomendasi pakar terlihat ada persamaan (similarity) dan saling melengkapi, sehingga dapat dipakai manajemen sebagai pilihan atribut tarif Rumah Sakit Islam di kota Depok. Manajemen Rumah Sakit Islam perlu mempertimbangkan potensi pasarnya dan merealisasikan atribut universal dan spesifik sehingga dapat memberikan pelayanan berkualitas.

\section{Daftar Pustaka}

1. Berkowitz, Eric N. Essentials of health care marketing. USA, Maryland:
An Aspen Publisher; 1996.

2. Kotler, P \& Clarke, R N. Marketing for health care organizations. USA, New Jersey; 1987.

3. Kasali, R. Membidik pasar indonesia: segmentasi, targeting \& positioning. Jakarta: PT Gramedia; 2005.

4. Kartajaya, H. Aa'Gym a spiritual marketer. Jakarta: MarkPlus \& co.; 2005.

5. Kartajaya, H; Syakir, M. Syariah marketing. Edisi Kedua. Bandung: Mizan; 2006.

6. Yusanto, M I, Karebet, M W. Menggagas bisnis islami. Cetakan Keenam. Gema Insani Press; 2006. 